\title{
Fluoxetine was safe and effective for body dysmorphic disorder
}

Phillips KA, Albertini RS, Rasmussen SA. A randomized placebo-controlled trial of fluoxetine in body dysmorphic disorder.
Arch Gen Psychiatry 2002 Apr;59:381-8.

\section{QUESTION: In patients with body dysmorphic disorder (BDD), is fluoxetine hydrochloride more effective than placebo?}

\section{Design}

Randomised (allocation concealed*), blinded (clinicians, patients, and outcome assessors)*, placebo controlled trial with 12 weeks of follow up.

\section{Setting}

An academic centre in Providence, Rhode Island, USA.

\section{Patients}

74 patients who had DSM-IV confirmed BDD with or without a delusional disorder for $\geq 6$ months, were $18-65$ years of age, scored $\geq 24$ on the Yale-Brown Obsessive Compulsive Scale Modified for Body Dysmorphic Disorder (BDD-YBOCS), and scored at least moderate on the Clinical Global Impression scale for BDD (BDD-CGI). Exclusion criteria included psychotic disorder not attributable to delusional BDD, bipolar disorder, alcohol or substance abuse in the previous 6 months, body image concerns better accounted for by an eating disorder, suicide attempt or ideation, recent use of certain psychiatric drugs or psychotherapy, and potential for pregnancy. 67 patients (mean age $32 \mathrm{y}, 69 \%$ women) were randomised and 59 (88\%) completed the trial.

\section{Intervention}

Patients completed a 1 week placebo run in period and were allocated to fluoxetine, $20 \mathrm{mg} /$ day, $(\mathrm{n}=34)$ or placebo $(n=33)$ for 2 weeks. The dose was increased by $20 \mathrm{mg}$ /day every 10 days to a maximum of $80 \mathrm{mg}$ /day.

\section{Main outcome measures}

Change on the BDD-YBOCS (clinical response was a $\geq 30 \%$ decrease in total score). Secondary outcomes were improvement on the BDD-CGI, depressive symptoms, psychosocial functioning, and adverse effects.

\section{Main results}

Analysis was by intention to treat. 27 patients (40\%) were delusional at baseline. Improvement on the BDDYBOCS was greater in the fluoxetine group than the placebo group; differences started at week $8(\mathrm{p}=0.04)$ and continued through to week $12(\mathrm{p}<0.001)$. Clinical response was greater in the fluoxetine group than the placebo group $(\mathrm{p}=0.003)$ (table). More patients who received fluoxetine were much or very much improved on the clinician rated $(\mathrm{p}=0.02)$ and patient rated $(p=0.02)$ BDD-CGI. Functional impairment was also more improved with fluoxetine $(\mathrm{p}<0.001)$, as were depressive symptoms $(\mathrm{p}=0.01)$. Patients who were delusional at baseline were as likely as non-delusional patients to respond to fluoxetine. Drowsiness and stomach or abdominal discomfort were the only adverse effects that occurred more frequently with fluoxetine $(\mathrm{p} \leq 0.01)$.

\section{Conclusion}

In delusional and non-delusional patients with body dysmorphic disorder, fluoxetine hydrochloride was more effective than placebo.

*See glossary.

Sources of funding:

National Institute of

Mental Health.

Fluoxetine and placebo

supplied by Eli Lilly.

For correspondence:

Dr K A Phillips, Butler

Hospital, Providence,

RI, USA

katharine_phillips@

brown.edu

Fluoxetine v placebo for body dysmorphic disorder at 12 weekst

\begin{tabular}{lllll} 
Outcome & Fluoxetine & Placebo & RBI (95\% Cl) & NNT (Cl) \\
$\begin{array}{l}\geq 30 \% \text { decrease on } \\
\text { BDD-YBOCS }\end{array}$ & $53 \%$ & $18 \%$ & $191 \%(40$ to 548$)$ & 3 (2 to 9$)$ \\
total score & & & & \\
\hline
\end{tabular}

†BDD-YBOCS = Yale-Brown Obsessive Compulsive Scale Modified for Body Dysmorphic Disorder. Other abbreviations defined in glossary; RBI, NNT, and Cl calculated from data in article.

\section{COMMENTARY}

BDD is a chronic and under recognised condition. Patients often present to dermatology and cosmetic surgery clinics rather than to psychiatry clinics. ${ }^{1}$ Untreated BDD and BDD treated with a non-psychiatric medical intervention have a poor outcome. ${ }^{1} \mathrm{BDD}$ has been considered a part of the obsessive compulsive disorder (OCD) spectrum, but also has high rates of comorbid depression. ${ }^{1}$ A crossover trial showed better outcomes with serotonergic reuptake inhibition. ${ }^{2}$ The study by Phillips $e t$ al is timely because it is the only randomised, placebo controlled trial of a serotonergic reuptake inhibitor for BDD.

In addition to screening for placebo responders, the study design also balanced the groups for OCD, depression, and delusionality. Although the outcome assessor was blind to adverse events, the individual was able to guess the patient allocation to treatment or placebo groups correctly in $69 \%$ of the cases.

The presence of depressive and obsessive symptoms did not predict the outcome, although change in depression scores correlated with improvement. Patients with delusional ideation responded to fluoxetine but not to placebo. However, the delusions themselves did not respond to treatment. Future trials may need to assess whether antipsychotic augmentation could alter delusional thinking. A role may exist for augmentation with cognitive behaviour therapy and other pharmacological agents to enhance response. Interestingly, open label fluoxetine treatment of placebo nonresponders yielded a $24 \%$ response rate. Insufficient information exists to conclude what the findings of the study would be if treatment dropouts were analysed as treatment failures.

This pivotal study provides a better alternative to expensive and ineffective medical or surgical interventions in patients with BDD. However, these results may apply only to specialist liaison settings because the general psychiatric practitioner may not encounter the diagnosis frequently enough.

In a national health service set-up, as in the UK, most of cosmetic surgery practice is based in the less regulated private sector ${ }^{3}$ often with self referred patients. This may make detection and appropriate treatment of BDD more difficult.

Sanjay Rao, MD, MRCPsych Royal Victoria Infirmary Newcastle-upon-Tyne, UK

Phillips KA, Rasmussen SA, Price LH. Treating imagined ugliness. Arch Gen Psychiatry 1999 Nov:56:1041-2.

2 Hollander E, Allen A, Kwon J, et al. Clomipramine vs desipramine crossover trial in body dysmorphic disorder: selective efficacy of a serotonin reuptake inhibitor in imagined uglidysmorphic disorder: selective efficacy of a serot
ness. Arch Gen Psychiatry 1999 Nov;56:1033-9.

Orton C. Regulating cosmetic surgery. BMJ 2002;324:1229-30. 